\title{
Predicting the visual acuity for retinal vein occlusion after ranibizumab therapy with an original ranking for macular microstructure
}

\author{
HAIYANG LIU, SUYAN LI, ZHENGPEI ZHANG and JIE SHEN \\ Department of Ophthalmology, Xuzhou First People's Hospital of Xuzhou Medical University, \\ Xuzhou Eye Research Institute, Xuzhou, Jiangsu 221002, P.R. China
}

Received June 9, 2017; Accepted October 5, 2017

DOI: $10.3892 /$ etm.2017.5437

\begin{abstract}
The study investigated predictive factors for best-corrected visual acuity (BCVA) after ranibizumab treatment in patients with macular edema (ME) associated with retinal vein occlusion (RVO) with an original ranking for the impairment of macular microstructure. In this retrospective study, 31 eyes of 31 patients with RVO received 3 monthly consecutive ranibizumab injections and another 3 months of follow-up. An original method was applied to rank the impairment of the external limiting membrane (ELM) and the ellipsoid zone (previously called the photoreceptor inner and outer segment junction, IS/OS) integrity on the baseline optical coherence tomography (OCT) images. Univariate and multivariate linear regression analyses were performed to assess the association between the baseline factors and post-treatment BCVA. ELM integrity and baseline BCVA were shown to be independent factors in the prediction of post-treatment BCVA. Comparison of post-treatment BCVA between original ELM ranks after adjusting for the baseline BCVA revealed the ELM integrity beneath the center of the fovea was important to post-treatment BCVA. ELM integrity in particular beneath the center of the fovea and baseline BCVA may be more useful than other factors in the prediction of visual function in patients with ME secondary to RVO after ranibizumab injections.
\end{abstract}

\section{Introduction}

Retinal vein occlusion (RVO) is one of most common vision-threatening retinal vascular diseases and can be divided

Correspondence to: Dr Suyan Li, Department of Ophthalmology, Xuzhou First People's Hospital of Xuzhou Medical University, Xuzhou Eye Research Institute, 19 Zhongshan Road, Xuzhou, Jiangsu 221002, P.R. China

E-mail: lishuyang1106@163.com

Key words: integrity of external limiting membrane, predictors, ranibizumab, retinal vein occlusion, visual acuity into two primary categories: i) Central retinal vein occlusion (CRVO) and ii) branch retinal vein occlusion (BRVO) (1). Previous studies have confirmed that the increased expression of angiogenic growth factors such as vascular endothelial cell growth factor (VEGF) caused by hypoxia secondary to RVO leads to vascular hyperpermeability with subsequent breakdown of the blood-retina barrier and macular edema (ME). The development of ME contributes to visual deterioration (2-5).

The introduction of VEGF inhibitors is the beginning of a new era in the treatment of ME secondary to RVO targeting the disease at the molecular level (6). Ranibizumab has been applied successfully to reduce ME due to RVO (7-13). However, treatment success is often temporary. Some patients experience no effect on the resolution of $\mathrm{ME}$, and some patients have a poor visual outcome despite complete resolution of the $\mathrm{ME}$ under ranibizumab therapy, despite multiple intravitreal injections. Therefore, the predictive factors for visual outcome after ranibizumab therapy have become very important (7,14-22).

Some factors are thought to be associated with the post-treatment best-corrected visual acuity (BCVA) prognosis of ME due to RVO under intravitreal anti-VEGF agent injections, such as the baseline BCVA, age, and macular microstructure (2). Optical coherence tomography (OCT) is a noninvasive method that visualizes the macular microstructure clearly. Spectral domain optical coherence tomography (SD-OCT) machines now attain $5 \mu \mathrm{m}$ resolution, which allows layer-by-layer evaluation of the retina, such as the ellipsoid zone, external limiting membrane (ELM), retina pigment epithelium (RPE), and choroid (23). Among these ocular structures, the central foveal thickness (CFT), ellipsoid zone, and ELM integrity were reported to be associated with post-treatment BCVA (24-27).

However, previously, the extent of the ellipsoid zone and ELM damage was assessed mainly by dividing the hyperreflective line within the $1 \mathrm{~mm}$ diameter circle centered on the fovea into completely visible, partially visible, and invisible (25). Thus, the important effect of integrity beneath the center of the fovea was not considered adequately, which is very important to visual acuity. In the present study, an original ranking was applied that the integrity of the ELM and the ellipsoid zone at baseline was categorized into four ranks: i) Completely visible line; ii) partially detectable line with undamaged center 


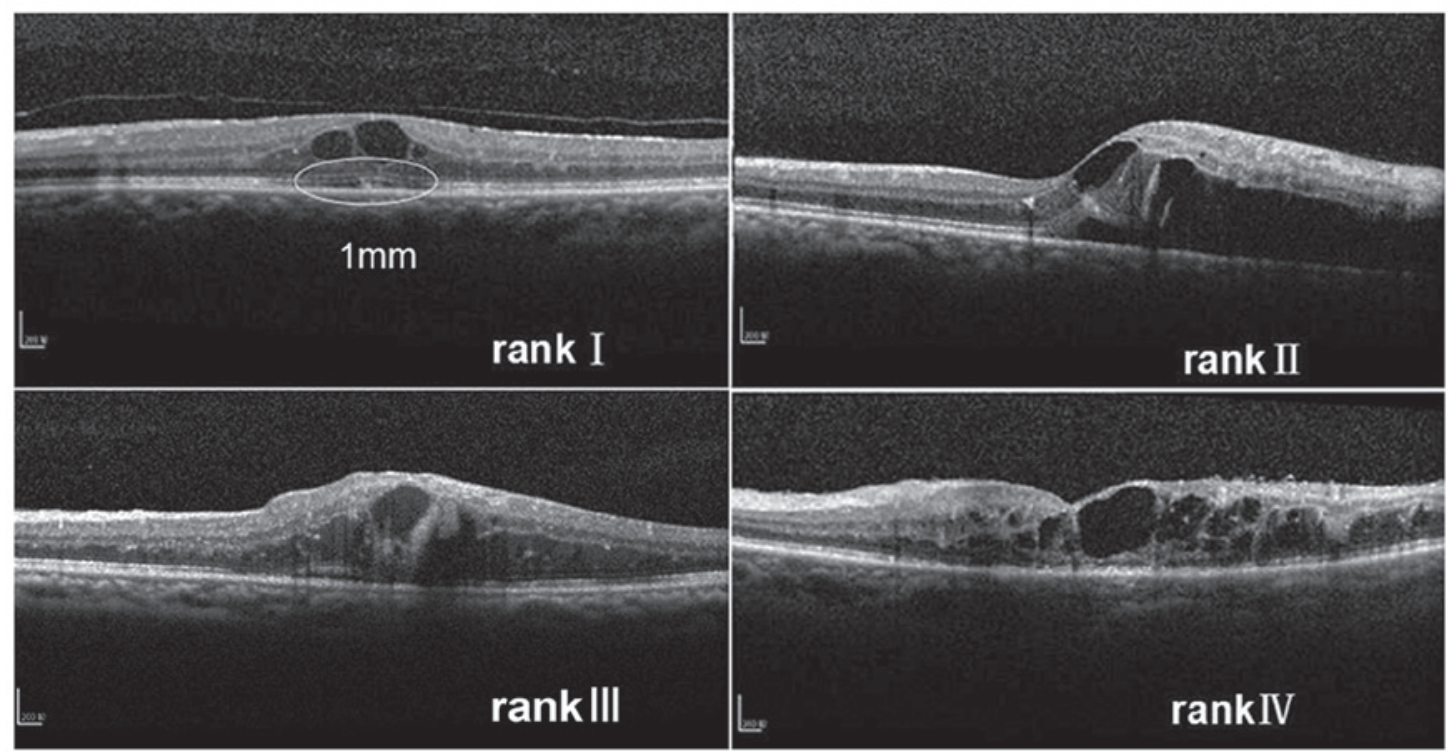

Figure 1. The representative figures of ranks of ELM integrity based on hyperreflective line within $1 \mathrm{~mm}$ diameter circle centered the fovea at baseline: Rank I, completely visible line; rank II, partially detectable line with undamaged center of fovea; rank III, partially detectable line with damaged center of fovea; rank IV, completely invisible line.

of fovea; iii) artially detectable line with damaged center of fovea; and iv) completely invisible line.

In this study, we applied the original ranking to investigate the effects of clinical baseline factors of eyes with $\mathrm{ME}$ secondary to RVO on post-treatment BCVA after 3 consecutive monthly ranibizumab injections and another 3 months of follow-up in order to find independent baseline characteristics that may predict a positive functional therapeutic response.

\section{Materials and methods}

In this retrospective study, 31 patients (16 CRVO, 15 BRVO) with ME due to RVO received 3 monthly consecutive intravitreal injections of $0.5 \mathrm{mg}$ ranibizumab and further 3 months of follow-up. During the follow-up period, subjects were eligible to receive monthly intraocular ranibizumab if they had $\mathrm{BCVA} \leq 20 / 40$ or $\mathrm{CFT} \geq 250 \mu \mathrm{m}$.

This study was approved by the Institutional Review Board and followed the tenets of the Declaration of Helsinki. Informed consent was obtained after patients were informed about the possible risks.

Patients were included if they met the inclusion criteria as follows: i) CFT on OCT was more than $300 \mu \mathrm{m}$; ii) the patient had not received an intravitreal injection; iii) 3 monthly consecutive ranibizumab injections and iv) other 3 months follow-up were completed, and no other treatment except ranibizumab injections was required. Patients were excluded if they had any of the following ocular diseases: Age-related macular degeneration (AMD), diabetic retinopathy (DR), choroidal neovascularization, a history of ocular trauma, and a history of intraocular surgery except cataract surgery. We also discharged patients if their baseline OCT scan did not provide an identifiable macular microstructure.

The patient's age, sex, and duration of RVO were recorded. A comprehensive ophthalmologic examination was performed. BCVA was measured with a Snellen chart and converted to a logarithm of the minimal angle of resolution ( $\log M A R)$ units for statistical analysis. Eyes that had post-treatment BCVA of better than $0.30 \log$ MAR were grouped in the good function group; the other eyes were grouped in the poor function group (28). Slit-lamp and fundus examinations were included. All patients underwent color fundus photography (Topcon Corp., Tokyo, Japan) and fluorescein angiography (FA; Heidelberg Engineering Inc., Heidelberg, Germany) to diagnose RVO and discover ischemic features. In addition, we performed SD-OCT imaging at baseline to evaluate the status of the ellipsoid zone, ELM, CFT, and subretinal hemorrhage within a $1 \mathrm{~mm}$ diameter circle centered on the fovea. All evaluations were obtained by authors masked to the patient's BCVA.

We obtained in each study eye 2 SD-OCT (spectralis; Heidelberg Engineering Inc.) scans $6 \mathrm{~mm}$ in crosshair fashion centered on the fovea (horizontal and vertical). For horizontal and vertical SD-OCT scans, the ART function (averaging of scans) was activated, and 25 SD-OCT scans were averaged. For maximal definition of the retinal layers, we used noise-reduction software (Heidelberg Engineering Inc.). The integrity of the ELM and the ellipsoid zone was categorized into four ranks depending on the microstructure within the $1 \mathrm{~mm}$ diameter circle centered on the fovea at baseline: i) Completely visible line, ii) partially detectable line with undamaged center of fovea, iii) partially detectable line with damaged center of fovea and iv) completely invisible line. If the ranking between the horizontal and vertical scans was different, the higher ranking was selected (Fig. 1).

All statistical analyses were performed using SPSS ver. 18.0 (SPSS, Inc., Chicago, IL, USA). Continuous values were compared using an independent-sample t-test or a one-way analysis of variance (ANOVA). A paired sample t-test was used to compare the post-treatment with the baseline values. A non-parametric test was used if the continuous variables were abnormally distributed. Categorical variables were assessed 
Table I. Baseline characteristics of patients with ME secondary to RVO.

\begin{tabular}{lc}
\hline No. of eyes (left/right) & $31(19 / 12)$ \\
\hline Age (years) & $61.4 \pm 9.7$ \\
Sex (Male/Female) & $13 / 18$ \\
CRVO/BRVO & $16 / 15$ \\
Duration of symptoms (days) & $104.0 \pm 89.0$ \\
Baseline BCVA (logMAR) & $0.60 \pm 0.26$ \\
Optical coherence tomography & \\
Initial ELM integrity & I 10, II 9, III 8, IV 4 \\
Initial ellipsoid zone integrity & I 6, II 9, III 11, IV 5 \\
Baseline central fovea thickness ( $\mu \mathrm{m})$ & $646.4 \pm 197.0$ \\
Hemorrhage under the fovea (yes/no) & $5 / 26$ \\
Fluorescein angiography & $13 / 18$ \\
Ischaemic/non-ischaemic type & $25 / 6$ \\
Intact/broken foveal capillary ring &
\end{tabular}

BCVA, best-corrected visual acuity; CRVO/BRVO, central retinal vein occlusion/branch retinal vein occlusion; ELM, external limiting membrane; ME, macular edema.

using the chi-squared test. To determine the independent baseline factors that predict post-treatment BCVA, univariate regression analysis was performed, followed by stepwise multivariate regression analysis, $\log$ MAR BCVA at 6 month after the first intravitreal injection was treated as a dependent variable. Analysis of covariance was used to calculate and compare post-treatment BCVA after adjusting for other variables between ELM ranks. A P $<0.05$ was considered to indicate a statistically significant analysis.

\section{Results}

A total of 31 eyes of 31 patients with RVO (13 men and 18 women) were included in this study. Table I shows the baseline characteristics of the 31 eyes. The mean age of the patients was $61.4 \pm 9.7$ years. Of all $31 \mathrm{RVO}$ eyes, 16 eyes were CRVO, and 15 eyes were BRVO. The mean interval from diagnosis to the 1st injection for the patients with RVO was $104.0 \pm 89.0$ days.

The mean post-treatment $\log$ MAR BCVA of the eyes was $0.34 \pm 0.24$ from $0.60 \pm 0.26$ at baseline (Fig. $2, \mathrm{P}<0.05$ ). The mean CFT decreased to $206.7 \pm 37.6 \mu \mathrm{m}$ from $646.4 \pm 197.0 \mu \mathrm{m}$ at baseline following 3 monthly ranibizumab injections and further 3 months of follow-up (Fig. 3, P<0.05).

Table II shows the general characteristics, BCVA, OCT, and FA data for the good function and poor function groups at baseline. There was no significant difference in the general characteristics between the groups, while significant differences in the baseline ELM integrity, ellipsoid zone integrity, and BCVA between the groups were observed. The results revealed the baseline ELM integrity, ellipsoid zone integrity, and BCVA of the good function were significantly better than those of the poor function group $(\mathrm{P}<0.01)$. Differences in the baseline CFT and FA data between groups were found but were not statistically significant.

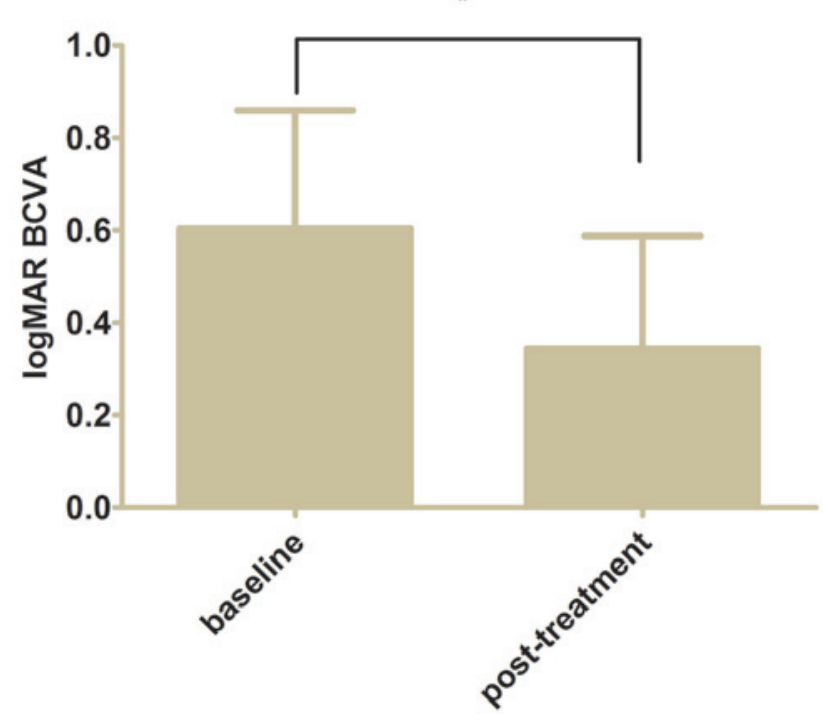

Figure 2. The mean BCVA changes from baseline to post-treatment, showing the post-treatment $\log \mathrm{MAR}$ BCVA was significantly better than the baseline $\log$ MAR BCVA. "P<0.05; BCVA, best-corrected visual acuity; $\log M A R$, logarithm of the minimal angle of resolution.

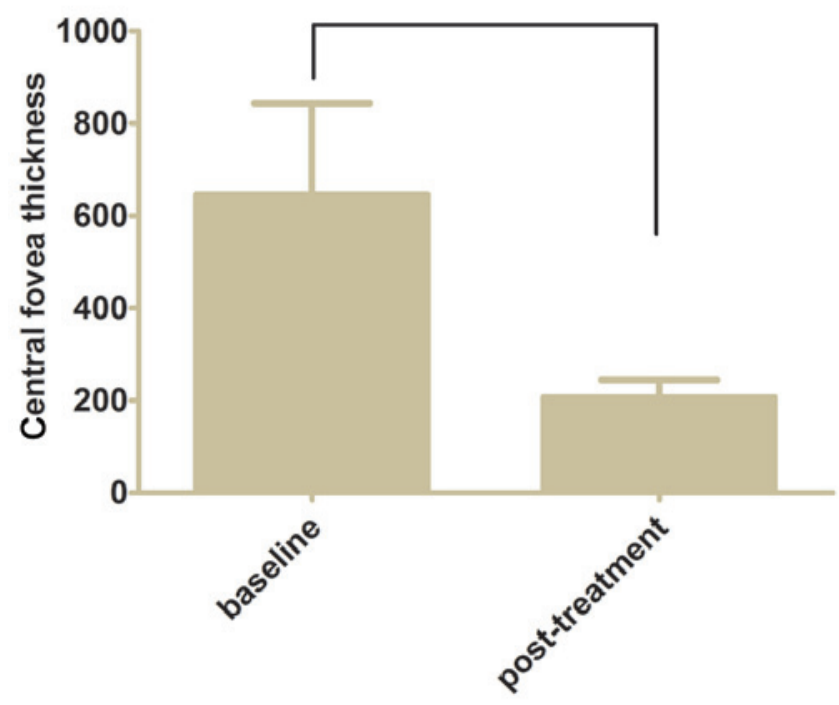

Figure 3. The mean CFT changes from baseline to post-treatment, demonstrating the post-treatment CFT was significantly thinner than the baseline CFT. "P $<0.05$; CFT, central foveal thickness.

Univariate and multivariate regression analyses were performed to determine the baseline factors significantly associated with post-treatment BCVA in all patients. Univariate regression analyses showed that the ellipsoid zone, ELM, baseline BCVA, sex, and RVO type were associated significantly with post-treatment BCVA $(\mathrm{P}<0.05)$. We then performed stepwise multivariate regression analyses to determine the baseline factors independently associated with post-treatment BCVA. The result showed that the ELM integrity and the baseline BCVA were the independent factors associated with post-treatment BCVA $(\mathrm{B}=0.149, \mathrm{P}<0.01 ; \mathrm{B}=0.262, \mathrm{P}=0.045$, respectively). Both were positively associated with post- 
Table II. Comparison of baseline characteristics between good function and poor function group.

\begin{tabular}{|c|c|c|c|}
\hline & Good function group & Poor function group & \\
\hline Baseline predictors & $\mathrm{N}=19$ & $\mathrm{~N}=12$ & P-value \\
\hline Age (years) & $60.1 \pm 10.1$ & $63.5 \pm 9.2$ & 0.354 \\
\hline Sex & & & 0.123 \\
\hline Male & 10 & 3 & \\
\hline Famale & 9 & 9 & \\
\hline Eye & & & 0.206 \\
\hline Left & 10 & 9 & \\
\hline Right & 9 & 3 & \\
\hline Type & & & 0.179 \\
\hline CRVO & 8 & 8 & \\
\hline BRVO & 11 & 4 & \\
\hline Duration of symptoms (days) & $88.7 \pm 84.9$ & $128.2 \pm 93.7$ & 0.236 \\
\hline Initial ELM integrity & I8, II9, III2, IV0 & I2, II0, III6, IV4 & $0.001^{\mathrm{a}}$ \\
\hline Initial ellipsoid zone integrity & I5, II9, III5, IV0 & I1, II0, III6, IV5 & $<0.01^{\mathrm{a}}$ \\
\hline Baseline central fovea thickness $(\mu \mathrm{m})$ & $640.2 \pm 143.7$ & $656.2 \pm 268.1$ & 0.951 \\
\hline Baseline BCVA & $0.47 \pm 0.13$ & $0.82 \pm 0.26$ & $<0.01^{\mathrm{a}}$ \\
\hline Hemorrhage under the fovea (Yes/No) & & & 0.949 \\
\hline Yes & 3 & 2 & \\
\hline No & 16 & 10 & \\
\hline Ischaemic/non-ischaemic type & & & 0.981 \\
\hline Yes & 8 & 5 & \\
\hline No & 11 & 7 & \\
\hline Intact/broken foveal capillary ring & & & 0.762 \\
\hline Yes & 4 & 2 & \\
\hline No & 15 & 10 & \\
\hline
\end{tabular}

BCVA, best-corrected visual acuity; CRVO/BRVO, central retinal vein occlusion/branch retinal vein occlusion; ELM, external limiting membrane; ${ }^{\mathrm{a}} \mathrm{P}<0.01$.

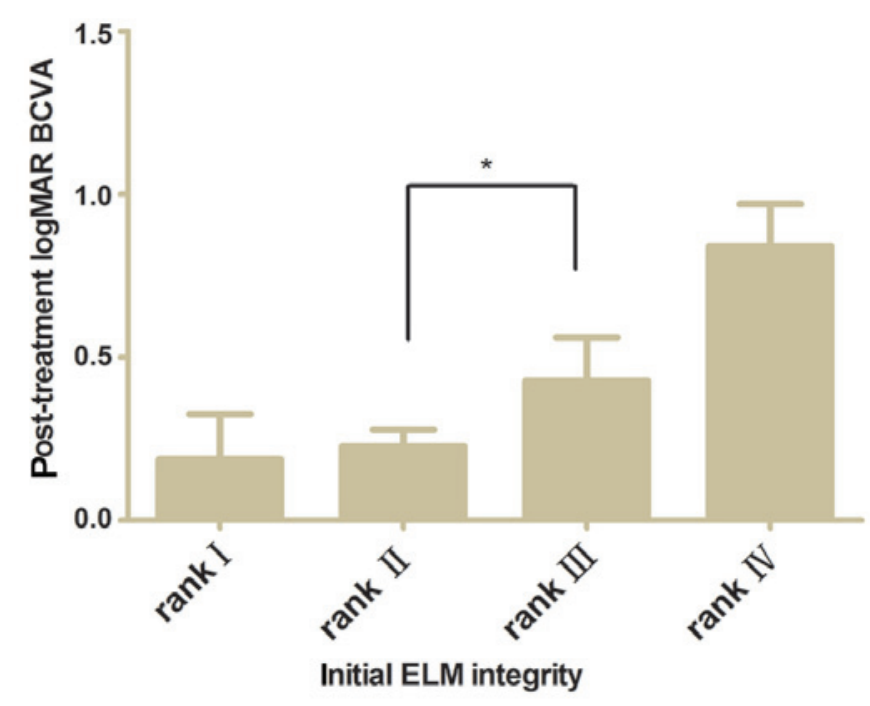

Figure 4. Comparison of post-treatment BCVA between ELM ranks after adjusting for initial BCVA, showing the post-treatment BCVA difference after adjusting for baseline BCVA between ranks II and III was significant $(\mathrm{P}=0.05) .{ }^{*} \mathrm{P}<0.05$; BCVA, best-corrected visual acuity; ELM, external limiting membrane. treatment BCVA. Tables III and IV show the detailed results of the regression analysis.

A comparison of post-treatment BCVA between the ELM ranks after adjusting for baseline BCVA was performed. The baseline BCVA was shown to be associated with post-treatment BCVA independently. Fig. 4 shows the post-treatment BCVA difference between ranks II and III was significant $(\mathrm{P}<0.05)$.

\section{Discussion}

In the present study, we investigated the baseline factors with an original ranking on OCT images to predict post-treatment BCVA after ranibizumab treatment in patients with ME associated with RVO. Our results showed the ELM integrity and the baseline BCVA were the independent factors that predict post-treatment BCVA, indicating patients with good baseline ELM integrity in particular beneath the center of the fovea and baseline BCVA would obtain good post-treatment BCVA after intravitreal VEGF inhibitor therapy.

RVO is an important cause of visual impairment, and ME secondary to RVO is the second most common major retinal vascular disease after DR 3-5. Previously, there were no effec- 
Table III. Univariate analysis results of baseline predictors for post-treatment BCVA.

\begin{tabular}{|c|c|c|c|}
\hline \multirow[b]{2}{*}{ Baseline predictors } & \multirow[b]{2}{*}{$\mathrm{N} / \mathrm{mean} \pm \mathrm{SD}$} & \multicolumn{2}{|c|}{ Post-treatment BCVA } \\
\hline & & $\mathrm{B}(95 \% \mathrm{CI})$ & P-value \\
\hline Age (years) & $61.4 \pm 9.7$ & $0.003(-0.006,0.013)$ & 0.460 \\
\hline Sex & & $0.188(0.018,0.358)$ & 0.032 \\
\hline Male & 13 & & \\
\hline Female & 18 & & \\
\hline Eye & & $-0.138(-0.317,0.042)$ & 0.127 \\
\hline Left & 19 & & \\
\hline Right & 12 & & \\
\hline Type & & $-0.174(-0.344,-0.004)$ & $0.045^{\mathrm{b}}$ \\
\hline CRVO & 16 & & \\
\hline BRVO & 15 & & \\
\hline Duration of symptoms (days) & $104.0 \pm 89.0$ & $0.000(-0.001,0.001)$ & 0.544 \\
\hline Initial ELM integrity & I 10, II 9, III 8, IV 4 & $0.189(0.138,0.241)$ & $<0.01^{\mathrm{a}}$ \\
\hline Initial ellipsoid zone integrity & I 6, II 9, III 11, IV 5 & $0.186(0.126,0.246)$ & $<0.01^{\mathrm{a}}$ \\
\hline Baseline central fovea thickness $(\mu \mathrm{m})$ & $646.4 \pm 197.0$ & $0.000(0.000,0.001)$ & 0.124 \\
\hline Baseline BCVA & $0.60 \pm 0.26$ & $0.642(0.374,0.909)$ & $<0.01^{\mathrm{a}}$ \\
\hline Hemorrhage under the fovea & & $-0.024(-0.272,0.223)$ & 0.841 \\
\hline Yes & 5 & & \\
\hline No & 26 & & \\
\hline Ischaemic/non-ischaemic type & & $-0.008(-0.192,0.177)$ & 0.932 \\
\hline Yes & 13 & & \\
\hline No & 18 & & \\
\hline Intact/broken foveal capillary ring & & $0.040(-0.190,0.270)$ & 0.726 \\
\hline Yes & 6 & & \\
\hline No & 25 & & \\
\hline
\end{tabular}

BCVA, best-corrected visual acuity; CRVO/BRVO, central retinal vein occlusion/branch retinal vein occlusion; ELM, external limiting membrane; SD, standard deviation; ${ }^{\mathrm{a}} \mathrm{P}<0.01,{ }^{\mathrm{b}} \mathrm{P}<0.05$.

Table IV. Multivariate analysis results of baseline predictors for post-treatment BCVA.

\begin{tabular}{lccc}
\hline $\begin{array}{l}\text { Baseline } \\
\text { predictors }\end{array}$ & $\mathrm{N} /$ mean \pm SD & $\frac{\text { Post-treatment BCVA }}{2}$ & P-value \\
\hline $\begin{array}{lccc}\text { Initial ELM integrity } \\
\text { Baseline BCVA }\end{array}$ & I 10, II 9, III 8, IV 4 & B (95\% CI) & $<0.01$ \\
\hline
\end{tabular}

BCVA, best-corrected visual acuity; CRVO/BRVO, central retinal vein occlusion/branch retinal vein occlusion; ELM, external limiting membrane; SD, standard deviation.

tive treatments for ME secondary to CRVO, while only grid laser photocoagulation was available to treat ME secondary to BRVO, but it reduced edema very slowly and provided benefit for only a few patients $(29,30)$. In 2009, the Standard Care vs. Corticosteroid for Retinal Vein Occlusion (SCORE) study recommended $1 \mathrm{mg}$ intravitreal triamcinolone acetonide (TA) for ME secondary to CRVO, although the risk of cataract and high intraocular pressure increased. TA injections were not superior to grid laser for ME secondary to BRVO (31). High VEGF concentrations were present in the eyes of patients with RVO, resulting in neovascularization and ME, and VEGF inhibitors can block this pathogenesis, representing the safe, latest, and effective treatment for RVO. VEGF inhibitors included bevacizumab and ranibizumab, which were reported to be superior in BCVA gains and CFT decrease to other treatment. Among these VEGF inhibitors, ranibizumab have been 
approved in the United States and the European Union for the treatment of ME secondary to RVO (7,14-21).

However, not all patients benefit from VEGF inhibitors, and sometimes, BCVA does not improve even if there is a significant decrease in CFT 2. Several studies have been conducted to identify predictive factors for good treatment response, and some baseline factors were thought to contribute to post-treatment BCVA after intravitreal injections of anti-VEGF agent for patients with ME due to RVO. The factors included age, baseline BCVA, ischemic areas, response to first injection, duration of occlusion, history of hypertension, hemorrhage under the fovea, and baseline OCT findings, which were thought to be one of most important predictors $(2,10,26,32)$.

Today, images with high resolution of the neural retina can be obtained in a non-invasive manner with OCT scanning, and the microstructure of the retina such as the ellipsoid zone, ELM, and RPE can be defined on OCT imaging (23). Changes in the macular microstructure can be detected by OCT in most eyes with RVO during an early stage and are believed to be important predictors for post-treatment BCVA after intravitreal injections of an anti-VEGF agent $(22,27,28,33,34)$.

In some studies, the CFT measured with OCT was found to be able to predict the post-treatment BCVA outcome in ME due to RVO after anti-VEGF agent injections $(33,34)$. However, some researchers concluded that the correlation between baseline CFT and BCVA after anti-VEGF agent injections was not significant (35). Similarly, a contradictory conclusion regarding the association between baseline CFT and BCVA after VEGF inhibitor injections in patients with AMD appeared. To interpret this contradiction, Oishi et al (36) pointed out the pattern of correlation was $\mathrm{V}$-shaped, and there was a negatively linear correlation in eyes with CRT $>203 \mu \mathrm{m}$ and a positively linear trend in eyes with CRT $\leq 203 \mu \mathrm{m}$. However, in the present study, the baseline CFT was more than $203 \mu \mathrm{m}$, and the correlation was not significant.

Previously, the integrity of the ellipsoid zone and the ELM was shown to be significantly associated with post-treatment BCVA after anti-VEGF agent injections in patients with RVO and AMD $(22,24,25,28,35,36)$. Some studies demonstrated the integrity of the ellipsoid zone was more highly associated with post-treatment BCVA than the ELM $(24,28,35)$; however, some studies reported the ELM was more useful in the prediction of post-treatment BCVA $(22,25,36)$. In the present study, the integrity of the ellipsoid zone and the ELM correlated significantly with post-treatment BCVA in univariate regression analysis, respectively, but the integrity of the ellipsoid zone was excluded from the independent variables in multivariate regression analysis. We found the ELM was more useful in the prediction of post-treatment BCVA in patients with ME due to RVO, and we agreed with the interpretation that ellipsoid zone status may be too sensitive to evaluate diseases that cause severe retinal damage such as AMD, retinal detachment (RD), and RVO 36. The ELM may be more useful in the evaluation of retinal damage of ME secondary to RVO than the ellipsoid zone.

This study revealed a significant correlation of baseline BCVA and post-treatment BCVA after intravitreal VEGF inhibitor injections for ME secondary to RVO in univariate and multivariate regression analysis, in accordance with previous studies (26).
The strengths of our study are as follows: i) The bias resulting from the type of agents was controlled; ranibizumab was the single anti-VEGF agent for intravitreal injections unlike most previous studies and ii) previously, the extent of the ellipsoid zone and ELM damage was assessed mainly by dividing the hyperreflective line into completely visible, partially visible, and invisible. Thus, the important effect of integrity beneath the center of the fovea was not considered adequately. In addition, the previous assessments were mainly based on post-treatment OCT imaging instead of baseline OCT imaging, so they could not be real predictors. In contrast, in the present study the integrity of the ELM and the ellipsoid zone at baseline was categorized into four ranks: i) Completely visible line), ii) partially detectable line with undamaged center of fovea), iii) partially detectable line with damaged center of fovea, and iv) completely invisible line. The results revealed the post-treatment BCVA in ELM rank II was significantly better than that of ELM rank III $(\mathrm{P}<0.05)$, which was attributed to the important effect of the ELM integrity beneath the center of the fovea.

In this study, we did not find a significant association between FA data and post-treatment BCVA, perhaps because the evaluation of the ischemia severity from baseline FA data was difficult, and nonischemic types could be incorrectly assessed as it would become ischemic type later. Of course, the small sample size and the retrospective design of this study might have affected our findings. Additional prospective investigation especially with large samples are needed to illuminate the predictors for BCVA after anti-VEGF agent treatment in patients with ME secondary to RVO.

In conclusion, the ELM integrity and the baseline BCVA may be more useful than other factors in the prediction of the post-treatment BCVA of patients with ME associated with RVO after intravitreal injections of ranibizumab, and the ELM integrity beneath the center of fovea should be the focus to predict post-treatment BCVA.

\section{Acknowledgements}

The present study was supported by Xuzhou Technology Program (XM13B077).

\section{References}

1. Huang P, Song Z and Sun X: Predictors of anti-vascular endothelial growth factor treatment responses in macular edema following central vein occlusion. Chin Med J (Engl) 127: 3019-3023, 2014

2. Huang P, Niu W, Ni Z, Wang R and Sun X: A meta-analysis of anti-vascular endothelial growth factor remedy for macular edema secondary to central retinal vein occlusion. PLoS One 8: e82454, 2013.

3. McIntosh RL, Rogers SL, Lim L, Cheung N, Wang JJ, Mitchell P, Kowalski JW, Nguyen HP and Wong TY: Natural history of central retinal vein occlusion: An evidence-based systematic review. Ophthalmology 117: 1113-1123, 2010.

4. Rogers SL, McIntosh RL, Lim L, Mitchell P, Cheung N, Kowalski JW, Nguyen HP, Wang JJ and Wong TY: Natural history of branch retinal vein occlusion: An evidence-based systematic review. Ophthalmology 117: 1094-1101, 2010.

5. Rogers S, McIntosh RL, Cheung N, Lim L, Wang JJ, Mitchell P, Kowalski JW, Nguyen H and Wong TY: International eye disease consortium: The prevalence of retinal vein occlusion: Pooled data from population studies from the United States, Europe, Asia and Australia. Ophthalmology 117: 313-319, 2010. 
6. Rosenfeld PJ, Fung AE and Puliafito CA: Optical coherence tomography findings after an intravitreal injection of bevacizumab (avastin) for macular edema from central retinal vein occlusion. Ophthalmic Surg Lasers Imaging 36: 336-339, 2005.

7. Brown DM, Campochiaro PA, Singh RP, Li Z, Gray S, Saroj N, Rundle AC, Rubio RG and Murahashi WY; Cruise Investigators: Ranibizumab for macular edema following central retinal vein occlusion: Six-month primary end point results of a phase III study. Ophthalmology 117: 1124-1133, 2010.

8. Demir M, Oba E, Gulkilik G, Odabasi M and Ozdal E: Intravitreal bevacizumab for macular edema due to branch retinal vein occlusion: 12-month results. Clin Ophthalmol 5: 745-749, 2011.

9. Figueroa MS, Contreras I, Noval S and Arruabarrena C: Results of bevacizumab as the primary treatment for retinal vein occlusions. Br J Ophthalmol 94: 1052-1056, 2010.

10. Gallego-Pinazo R, Dolz-Marco R, Pardo-Lopez D, Martinez-Castillo S, Lleo-Perez A, Arevalo JF and Diaz-Llopis M: Ranibizumab for serous macular detachment in branch retinal vein occlusions. Graefes Arch Clin Exp Ophthalmol 251: 9-14, 2013.

11. Prager F, Michels S, Kriechbaum K, Georgopoulos M, Funk M, Geitzenauer W, Polak K and Schmidt-Erfurth U: Intravitreal bevacizumab (Avastin) for macular oedema secondary to retinal vein occlusion: 12-month results of a prospective clinical trial. $\mathrm{Br}$ J Ophthalmol 93: 452-456, 2009.

12. Spaide RF, Chang LK, Klancnik JM, Yannuzzi LA, Sorenson J, Slakter JS, Freund KB and Klein R: Prospective study of intravitreal ranibizumab as a treatment for decreased visual acuity secondary to central retinal vein occlusion. Am J Ophthalmol 147: 298-306, 2009

13. Gregori NZ, Rattan GH, Rosenfeld PJ, Puliafito CA Feuer W, Flynn HW Jr, Berrocal AM, Al-Attar L, Dubovy S, Smiddy WE, et al: Safety and efficacy of intravitreal bevacizumab (avastin) for the management of branch and hemiretinal vein occlusion. Retina 29: 913-925, 2009.

14. Boyd SR, Zachary I, Chakravarthy U, Allen GJ, Wisdom GB Cree IA, Martin JF, Hykin PG. Correlation of increased vascular endothelial growth factor with neovascularization and permeability in ischemic central vein occlusion. Arch Ophthalmol 120 : 1644-1650, 2002.

15. Campochiaro PA, Brown DM, Awh CC, Lee SY, Gray S, Saroj N, Murahashi WY and Rubio RG: Sustained benefits from ranibizumab for macular edema following central retinal vein occlusion: Twelve-month outcomes of a phase III study. Ophthalmology 118: 2041-2049, 2011.

16. Campochiaro PA, Heier JS, Feiner L, Gray S, Saroj N, Rundle AC, Murahashi WY and Rubio RG; BRAVO Investigators: Ranibizumab for macular edema following branch retinal vein occlusion: Six-month primary end point results of a phase III study. Ophthalmology 117: 1102-1112, 2010.

17. Campochiaro PA, Sophie R, Pearlman J, Brown DM, Boyer DS Heier JS, Marcus DM, Feiner L and Patel A; RETAIN Study Group: Long-term outcomes in patients with retinal vein occlusion treated with ranibizumab: The RETAIN study. Ophthalmology 121: 209-219, 2014.

18. Glanville J, Patterson J, McCool R, Ferreira A, Gairy K and Pearce I: Efficacy and safety of widely used treatments for macular oedema secondary to retinal vein occlusion: A systematic review. BMC Ophthalmol 14: 7, 2014

19. Kinge B, Stordahl PB, Forsaa V, Fossen K, Haugstad M, Helgesen $\mathrm{OH}$, Seland J and Stene-Johansen I: Efficacy of ranibizumab in patients with macular edema secondary to central retinal vein occlusion: Results from the sham-controlled ROCC study. Am J Ophthalmol 150: 310-314, 2010.

20. Regnier SA, Larsen M, Bezlyak V and Allen F: Comparative efficacy and safety of approved treatments for macular oedema secondary to branch retinal vein occlusion: A network meta-analysis. BMJ Open 5: e007527, 2015.

21. Thom HH, Capkun G, Nixon RM and Ferreira A: Indirect comparisons of ranibizumab and dexamethasone in macular oedema secondary to retinal vein occlusion. BMC Med Res Methodol 14: 140, 2014.
22. Wolf-Schnurrbusch UE, Ghanem R, Rothenbuehler SP, Enzmann V, Framme C and Wolf S: Predictors of short-term visual outcome after anti-VEGF therapy of macular edema due to central retinal vein occlusion. Invest Ophthalmol Vis Sci 52: 3334-3337, 2011

23. Keane PA and Sadda SR: Predicting visual outcomes for macular disease using optical coherence tomography. Saudi J Ophthalmol 25: 145-158, 2011.

24. Ota M, Tsujikawa A, Murakami T, Kita M, Miyamoto K, Sakamoto A, Yamaike N and Yoshimura N: Association between integrity of foveal photoreceptor layer and visual acuity in branch retinal vein occlusion. Br J Ophthalmol 91: 1644-1649, 2007.

25. Shin HJ, Chung H and Kim HC: Association between integrity of foveal photoreceptor layer and visual outcome in retinal vein occlusion. Acta Ophthalmol 89: e35-e40, 2011.

26. Jaissle GB, Szurman P, Feltgen N, Spitzer B, Pielen A, Rehak M, Spital G, Heimann H and Meyer CH: Retinal vein occlusion study group: Predictive factors for functional improvement after intravitreal bevacizumab therapy for macular edema due to branch retinal vein occlusion. Graefes Arch Clin Exp Ophthalmol 249: 183-192, 2011

27. Bhisitkul RB, Campochiaro PA, Shapiro H and Rubio RG: Predictive value in retinal vein occlusions of early versus late or incomplete ranibizumab response defined by optical coherence tomography. Ophthalmology 120: 1057-1063, 2013.

28. Sakamoto A, Tsujikawa A, Ota M, Yamaike N, Kotera Y, Miyamoto K, Kita M and Yoshimura N: Evaluation of potential visual acuity in eyes with macular oedema secondary to retinal vein occlusion. Clin Experiment Ophthalmol 37: 208-216, 2009.

29. Clarkson JG, Chuang E, Gass D, Pedroso M, Cubillas T, Duria ES, Hess DJ, Rams I, Ball M, Gutierrez A, et al: Evaluation of grid pattern photocoagulation for macular edema in central vein occlusion. The central vein occlusion study group $\mathrm{M}$ report. Ophthalmology 102: 1425-1433, 1995.

30. Battaglia Parodi M, Saviano S and Ravalico G: Grid laser treatment in macular branch retinal vein occlusion. Graefes Arch Clin Exp Ophthalmol 237: 1024-1027, 1999.

31. Ip MS, Scott IU, Van Veldhuisen PC, Oden NL, Blodi BA, Fisher M, Singerman LJ, Tolentino M, Chan CK and Gonzalez VH: A randomized trial comparing the efficacy and safety of intravitreal triamcinolone with observation to treat vision loss associated with macular edema secondary to central retinal vein occlusion: The standard care vs corticosteroid for retinal vein occlusion (SCORE) study report 5. Arch Ophthalmol 127: 1101-1114, 2009.

32. Zhao L, Li B, Feng K, Han L, Ma Z and Liu Y: Bevacizumab treatment for acute branch retinal vein occlusion accompanied by subretinal hemorrhage. Curr Eye Res 40: 752-756,2015.

33. Ach T, Hoeh AE, Schaal KB, Scheuerle AF and Dithmar S: Predictive factors for changes in macular edema in intravitreal bevacizumab therapy of retinal vein occlusion. Graefes Arch Clin Exp Ophthalmol 248: 155-159, 2010.

34. Hoeh AE, Ruppenstein M, Ach T and Dithmar S: OCT patterns of macular edema and response to bevacizumab therapy in retinal vein occlusion. Graefes Arch Clin Exp Ophthalmol 248: $1567-1572,2010$

35. Kang HM, Chung EJ, Kim YM and Koh HJ: Spectral-domain optical coherence tomography (SD-OCT) patterns and response to intravitreal bevacizumab therapy in macular edema associated with branch retinal vein occlusion. Graefes Arch Clin Exp Ophthalmol 251: 501-508, 2013.

36. Oishi A, Hata M, Shimozono M, Mandai M, Nishida A and Kurimoto Y: The significance of external limiting membrane status for visual acuity in age-related macular degeneration. Am J Ophthalmol 150: 27-32, 2010

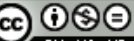

This work is licensed under a Creative Common Attribution-NonCommercial-NoDerivatives 4.0 International (CC BY-NC-ND 4.0) License. 